\title{
Does Regular Surveillance Improve the Long-Term Survival of Arteriovenous Fistulas?
}

\author{
Ashwin Shetty and William L. Whittier \\ Division of Nephrology, Department of Internal Medicine, Rush University Medical Center, Chicago, IL 60607, USA \\ Correspondence should be addressed to William L. Whittier, william_whittier@rush.edu \\ Received 6 September 2011; Accepted 21 October 2011 \\ Academic Editor: Anil K. Agarwal
}

Copyright ( $) 2012$ A. Shetty and W. L. Whittier. This is an open access article distributed under the Creative Commons Attribution License, which permits unrestricted use, distribution, and reproduction in any medium, provided the original work is properly cited.

The rate of arteriovenous fistula (AVF) placement continues to rise and AVF failure is a major complication. The main cause of AVF failure is stenosis leading to thrombosis. Although the detection of early stenosis with preemptive correction prior to thrombosis seems to be a plausible option to prevent access failure, there is much debate, on the basis of studies of surveillance with arteriovenous grafts, as to whether early surveillance actually improves the longevity of AVFs. Evaluating the available information for surveillance, specifically the data for AVF stenosis and survival, is necessary to determine if surveillance is warranted. These trials have shown that vascular access flow (Qa) surveillance is beneficial in revealing subclinical stenosis. Preemptive angioplasty and surgical revision have shown to decrease thrombosis rates. However, at the present time, there is only limited data on whether preemptive treatment equates to improved long-term AVF survival.

\section{Introduction}

The occurrence of end-stage renal disease (ESRD) and dialysis access placement in the United States continues to increase [1]. Due to the superior long-term patency, lower complications, and decreased mortality rates, arteriovenous fistulas (AVFs) are the access of choice and represent $41.3 \%$ of the total hemodialysis accesses in the United States $[1,2]$. Even as the rate of fistula placement improves, hemodialysis access failure continues to be a leading cause of hospitalizations and morbidity in the dialysis population [1]. The development of significant stenosis leading to poor flow and thrombosis is a leading cause of AVF revision and failure [2]. Although the detection of early stenosis with preemptive surgical correction or angioplasty prior to thrombosis seems to be a plausible option to prevent access failure, there is much debate as to whether early surveillance actually improves the longevity of AVFs.

There are many noninvasive methods available for the surveillance of stenosis (Table 1). Clinical monitoring is a useful technique that involves physical examination of the access site, excessive bleeding from the AVF venopuncture site, difficult cannulation, or unexplained reduction of urea reduction ratio (URR). Other surveillance methods are available including access recirculation, flow studies, pressure studies and direct visualization by Doppler ultrasonography [3]. These various methods of surveillance have been studied and are all predictive of stenosis [4, 5]. This has led to the guidelines by the National Kidney Foundation Dialysis Outcomes Quality Initiatives (K/DOQI) advocating routine surveillance of AVFs and arteriovenous grafts (AVGs) in dialysis centers [6].

Surveillance of AVGs and AVFs is defined separately by the K/DOQI guidelines and studies have shown different results in these two distinct access groups [6]. In AVGs, there has been considerable debate on the validity of surveillance for thrombosis. Initial observational studies revealed a reduction in graft thrombosis with routine surveillance programs and preemptive angioplasty [7]. However, this was not confirmed by randomized controlled trials, as surveillance and preemptive angioplasty failed to lower thrombosis rates or improve long-term graft survival [7]. Therefore, the recommendation of routine surveillance for AVGs [6] has been questioned [3]. 
TAble 1: Noninvasive methods of surveillance for AV access stenosis.

\begin{tabular}{l}
\hline Clinical monitoring \\
Access recirculation \\
Flow studies \\
Sodium, urea, glucose, differential conductivity, inline \\
dialysance, ultrasound dilution and thermal methods \\
Pressure studies \\
Dynamic \\
Static \\
Direct visualization \\
Doppler ultrasonography \\
Magnetic resonance angiography \\
\hline
\end{tabular}

Debate also exists surrounding surveillance for AVFs on eventual thrombosis or fistula longevity. Measurement of vascular access flow $(\mathrm{Qa})$ is the recommended method of surveillance for AVFs, and much of this data is based on the observational studies in AVGs [6]. There have been numerous observational studies with historical control groups evaluating the benefit of Qa surveillance in AVFs, and results have been mixed [8-13]. Few of these studies [10-13] showed decreased thrombosis rates, while others $[8,9]$ showed no improvement [14]. Evaluating the available randomized controlled trials can better assess the question of whether the use of surveillance leads to a significant decrease in the rate of AVF thrombosis and improves longterm survival.

\section{Randomized Controlled Trials}

To date, there are four randomized trials that evaluated surveillance of AVF for stenosis and two of these evaluated the effect of prophylactic angioplasty on thrombosis rates and long-term outcomes (Table 2). In the most recent study, investigators randomly assigned 137 patients with AVFs to two groups: a group of monthly surveillance with Qa and clinical criteria and a control group with clinical criteria alone [15]. The clinical criteria consisted of an increase in dynamic venous pressures, decrease in blood flow $(\mathrm{Qb})$, excessive bleeding from venopuncture sites or unexplained reduction in URR. The patients in the Qa surveillance arm were referred to angiography if their Qa was $<500 \mathrm{~mL} / \mathrm{min}$ or if it fell by $>20 \%$ once the access flow was $<1,000 \mathrm{~mL} / \mathrm{min}$. Each group was referred for any changes in clinical criteria. The primary end point was time to detection of a stenotic lesion that was $\geq 50 \%$. Although thrombosis rates and AVF longevity were not reported in this study, the patients in the Qa surveillance arm were twice as likely to have stenosis detected compared to the control group.

The more relevant outcome of thrombosis rates were evaluated in a separate trial [16]. This study [16] included 103 patients of whom 68 had AVFs and 35 had AVGs. They were randomized into two major groups: one with monthly surveillance by Qa or static venous pressure and a control group. All patients underwent color flow Doppler ultrasound every 6 months. Patients with Qa $<750 \mathrm{~mL} / \mathrm{min}$ or static venous pressure ratios $\geq 0.5$ were referred for angiography. Using Doppler ultrasound, AVFs with $>50 \%$ stenosis, Qa $<600 \mathrm{~mL}$, or greater than $25 \%$ decline in Qa were also referred for angiography. If there was evidence of a stenotic lesion $\geq 50 \%$ of the vessel diameter, the patients underwent angioplasty. The primary end point was AVF thrombosis. Access longevity was not studied, but patients with AVFs followed with monthly surveillance by $\mathrm{Qa}$ and/or static venous pressure had a lower total thrombosis rate than the control patients (16.8 versus 27.1 per 100 patient years; $P<$ $0.05)$.

These studies revealed that surveillance using Qa detects early stenosis and leads to decreased thrombosis rates, but is there any long-term benefit for early intervention in patients with subclinical stenotic AVFs? This was evaluated in a trial [17] that included 60 patients with a stenotic lesion of $>50 \%$ by angiogram who were randomized into a treatment group that underwent percutaneous transluminal angioplasty (PTA) or a control group with no intervention. Patients were initially screened with measurements of blood flow ( $\mathrm{Qb}$ decrease by $>30 \mathrm{~mL} / \mathrm{min}$ on two consecutive hemodialysis sessions), access flow $(\mathrm{Qa}<850 \mathrm{~mL} / \mathrm{min})$ or urea-based access recirculation. If there was an abnormality, these patients were sent for fistulography, and if $>50 \%$ stenosis was found, they underwent randomization. All the AVFs with stenotic lesions were considered to be functional if they were providing adequate dialysis. The study end point was thrombosis or surgical revision due to inadequate dialysis. Impressively, the median functional failure-free AVF survival was 84 months (51.8 to 116.2 months) in the PTA group and 21 months (9.8 to 32.2 months) in controls $(P<0.001)$. A total of 6 patients in the PTA group had thrombosis compared to 14 patients in the control group $(P=0.029)$. However, the proportion of patients undergoing elective surgery was comparable. Therefore, early intervention in stenotic AVFs led to decreased time to and rates of thrombosis.

Surveillance of AVFs and early intervention has been shown to be successful in detecting stenosis and preventing thrombosis, but does identifying a significant stenosis lead to an increase in longevity of the access? A follow-up study from the same institution was performed shortly after in 2004 [18]. This study design was similar to the prior study. It included 79 patients with a significantly stenotic lesion who were randomized into treatment (PTA or surgical revision) or control group. The stenotic lesion was identified as in the above study with the only difference now being a $\mathrm{Qa}<750 \mathrm{~mL} / \mathrm{min}$. One unique variation in the study protocol was that the treatment and control group were further divided into a "functional" (Qa $>350 \mathrm{~mL} / \mathrm{min}$ ) or "failing" ( $\mathrm{Qa} \leq 350 \mathrm{~mL} / \mathrm{min})$ group. The primary end point was primary patency as defined by the interval from stenosis to access failure. The primary patency rates were higher in the treatment groups compared to the control for both functional $(P=0.021)$ and failing subgroups $(P=0.005)$. Access survival rates were significantly higher in the treatment group than the control group $(P=0.050)$. Interestingly, within the treatment group, survival rates 
TABLE 2: Randomized controlled trials of arteriovenous fistula surveillance.

\begin{tabular}{|c|c|c|c|c|c|c|}
\hline Name & Survey method & $\begin{array}{c}\text { Preemptive } \\
\text { angioplasty/surgical } \\
\text { revison }\end{array}$ & Control group & $\begin{array}{l}\text { Treatment } \\
\text { group }\end{array}$ & $\begin{array}{l}\text { Reduce } \\
\text { thrombosis }\end{array}$ & $\begin{array}{l}\text { Prolong } \\
\text { survival }\end{array}$ \\
\hline $\begin{array}{l}\text { Polkinghorne et } \\
\text { al.[15] }\end{array}$ & $\begin{array}{l}\mathrm{Qa}(<550 \mathrm{~mL} / \mathrm{min}) \text { and Clinical } \\
\text { criteria versus Clinical criteria } \\
\text { alone }\end{array}$ & No & 68 & 69 & * & $*$ \\
\hline Sands et $1 .[16]$ & $\begin{array}{l}\mathrm{Qa}(<800 \mathrm{~mL} / \mathrm{min}), \text { Static venous } \\
\text { pressure and Doppler ultrasound } \\
\text { versus Doppler ultrasound alone }\end{array}$ & No & 40 & 63 & Yes & * \\
\hline Tessitore et al. [17] & $\begin{array}{l}\mathrm{Qa}(<850 \mathrm{~mL} / \mathrm{min}), \mathrm{Qb}, \mathrm{Ru} \text {, and } \\
\text { Rhd }\end{array}$ & Yes & 30 & 32 & Yes & $*$ \\
\hline Tessitore et al. [18] & $\mathrm{Qa}(<750 \mathrm{~mL} / \mathrm{min}), \mathrm{Qb}$, and $\mathrm{Ru}$ & Yes & 36 & 43 & Yes & Yes \\
\hline
\end{tabular}

* Data/values not reported or unavailable.

Qa: vascular access flow, Qb: blood flow, Ru: urea-based access recirculation, and Rhd: ultrasound dilution recirculation.

were also higher in the functional subgroup compared to the failing one $(P=0.033)$. This study showed that early intervention on stenotic AVFs leads to increased longevity. If intervention is delayed until Qa flow is too low, then the AVF was not as salvageable with intervention.

When, then, is the appropriate time to intervene? Should prophylactic correction of subclinical stenosis become universal when a low $\mathrm{Qa}$ is detected? The two trials that evaluated preemptive treatment of subclinical stenosis showed decreased thrombosis rates $[17,18]$. In both trials, the majority of patients were sent to angiography, because their Qa was $<850 \mathrm{~mL} / \mathrm{min}$ or $750 \mathrm{~mL} / \mathrm{min}$, further validating the importance of using a surveillance program. The current guidelines recommend correction only in poorly functioning AVFs that are causing clinical compromise [6]. These trials show that preemptive treatment of stenosis detected by surveillance, prior to clinical consequences, is beneficial and in one trial [18], preemptive treatment was better when the $\mathrm{Qa}>350 \mathrm{~mL} / \mathrm{min}$. Once the Qa became lower than this threshold, the access was past the point of repair.

One of the major limitations of universally recommending preemptive intervention is that there is a paucity of information on long-term survival, as only one study evaluated this [18]. Even in that study, over a quarter of the treatment group underwent surgical revision as opposed to PTA [19] that may have contributed to these AVFs surviving longer. In fact, one study [16] revealed an increased restenosis rate after PTA.

The key question of whether detection of stenosis and early intervention increases the longevity of AVFs is unfortunately still not answered. Even though thrombosis rates have been lower in all studies, if there is no correlation to longer AVF survival, the beneficial effect may be inconsequential. If there is no benefit of access survival with surveillance, increased studies and interventions only consume more resources and add to cost. The method of repair (PTA or surgical) is also relevant. Although the available information suggests a benefit with surveillance, there needs to be larger, powered randomized trials on the long-term survival of AVF to conclusively settle the issue of the use of surveillance leading to longer AVF survival.

\section{Conclusion}

Observational studies have shown mixed results for the use of Qa surveillance in preventing AVF thrombosis. Randomized controlled trials, though, have shown that Qa surveillance is beneficial in revealing subclinical stenosis. Preemptive angioplasty and surgical revision have shown to decrease thrombosis rates. Larger, randomized controlled trials need to be done to show whether preemptive treatment equates to improved long-term AVF survival.

\section{References}

[1] US Renal Data System: USRDS Annual Data Report, The National Institutes of Health, National Institute of Diabetes and Digestive and Kidney Disease, Bethesda, Md, USA, 2010.

[2] M. Allon and M. L. Robbin, "Increasing arteriovenous fistulas in hemodialysis patients: problems and solutions," Kidney International, vol. 62, no. 4, pp. 1109-1124, 2002.

[3] W. L. Whittier, "Should arteriovenous access flow undergo regular surveillance?" Seminars in Dialysis, vol. 24, no. 4, pp. 389-390, 2011.

[4] W. L. Whittier, "Surveillance of hemodialysis vascular access," Seminars in Interventional Radiology, vol. 26, no. 2, pp. 130138, 2009.

[5] W. L. Whittier, H. A. Mansy, D. R. Rutz, A. M. Lewis, and R. H. Sandler, "Comparison of hemodialysis access flow measurements using flow dilution and in-line dialysance," ASAIO Journal, vol. 55, no. 4, pp. 369-372, 2009.

[6] National Kidney Foundation K/DOQI, "Clinical Practice Guideline and Clinical Practice Recommendations for vascular access 2006," American Journal of Kidney Disease, vol. 48, supplement 1, pp. S176-S273, 2006.

[7] M. Allon, "Do we really need periodic monitoring of vascular access for hemodialysis," Nephrology Self-Assessment Program, vol. 6, pp. 111-116, 2007.

[8] E. Wijnen, N. Planken, X. Keuter et al., "Impact of a quality improvement programme based on vascular access flow monitoring on costs, access occlusion and access failure," Nephrology Dialysis Transplantation, vol. 21, no. 12, pp. 35143519, 2006.

[9] H. Shahin, G. Reddy, M. Sharafuddin, D. Katz, B. S. Franzwa, and B. S. Dixon, "Monthly access flow monitoring with increased prophylactic angioplasty did not improve fistula 
patency," Kidney International, vol. 68, no. 5, pp. 2352-2361, 2005.

[10] P. Mccarley, R. L. Wingard, Y. Shyr, W. Pettus, R. M. Hakim, and T. Alp Ikizler, "Vascular access blood flow monitoring reduces access morbidity and costs," Kidney International, vol. 60, no. 3, pp. 1164-1172, 2001.

[11] B. Branger, C. Granolleras, M. Dauzat et al., "Hemodialysis arteriovenous fistula thrombosis frequency: contribution of doppler and ultrasound dilution technique," Nephrologie, vol. 25, no. 1, pp. 17-22, 2004.

[12] S. J. Schwab, M. J. Oliver, P. Suhocki, and R. McCann, "Hemodialysis arteriovenous access: detection of stenosis and response to treatment by vascular access blood flow," Kidney International, vol. 59, no. 1, pp. 358-362, 2001.

[13] C. E. Lok, C. Bhola, R. Croxford, and R. M. A. Richardson, "Reducing vascular access morbidity: a comparative trial of two vascular access monitoring strategies," Nephrology Dialysis Transplantation, vol. 18, no. 6, pp. 1174-1180, 2003.

[14] N. Tessitore, V. Bedogna, A. Poli et al., "Adding access blood flow surveillance to clinical monitoring reduces thrombosis rates and costs, and improves fistula patency in the short term: a controlled cohort study," Nephrology Dialysis Transplantation, vol. 23, no. 11, pp. 3578-3584, 2008.

[15] K. R. Polkinghorne, K. K. P. Lau, A. Saunder, R. C. Atkins, and P. G. Kerr, "Does monthly native arteriovenous fistula bloodflow surveillance detect significant stenosis-a randomized controlled trial," Nephrology Dialysis Transplantation, vol. 21, no. 9, pp. 2498-2506, 2006.

[16] J. J. Sands, P. A. Jabyac, C. L. Miranda, and B. J. Kapsick, "Intervention based on monthly monitoring decreases hemodialysis access thrombosis," ASAIO Journal, vol. 45, no. 3, pp. 147-150, 1999.

[17] N. Tessitore, G. Mansueto, V. Bedogna et al., "A prospective controlled trial on effect of percutaneous transluminal angioplasty on functioning arteriovenous fistulae survival," Journal of the American Society of Nephrology, vol. 14, no. 6, pp. 1623$1627,2003$.

[18] N. Tessitore, G. Lipari, A. Poli et al., "Can blood flow surveillance and pre-emptive repair of subclinical stenosis prolong the useful life of arteriovenous fistulae? A randomized controlled study," Nephrology Dialysis Transplantation, vol. 19, no. 9, pp. 2325-2333, 2004.

[19] C. D. Cipleu, G. V. Cherla, D. Merrill et al., "Can blood flow surveillance and pre-emptive repair of subclinical stenosis prolong the useful life of arteriovenous fistulae? A randomized controlled study," Nephrology Dialysis Transplantation, vol. 20, no. 1, pp. 241-243, 2005. 


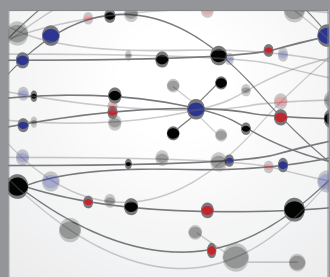

The Scientific World Journal
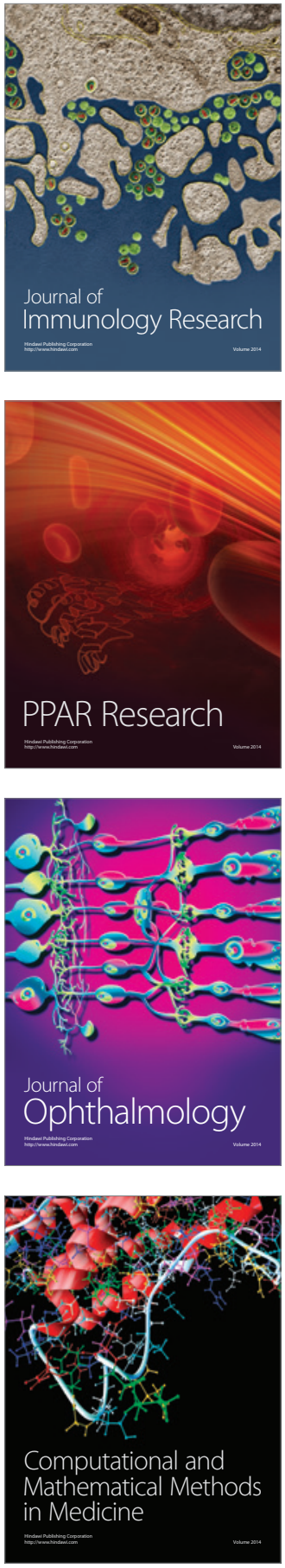

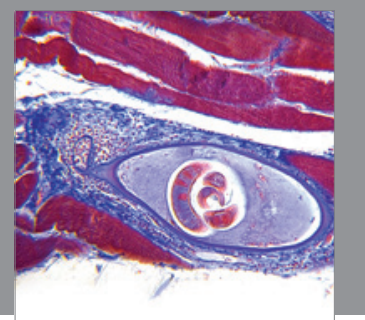

Gastroenterology

Research and Practice
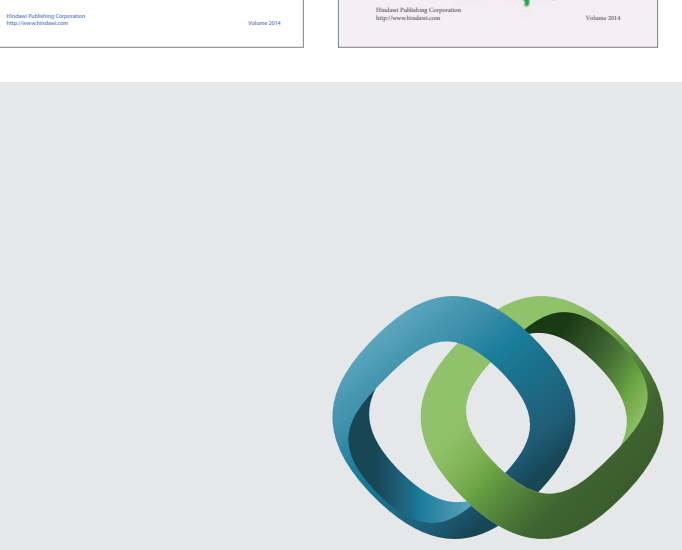

\section{Hindawi}

Submit your manuscripts at

http://www.hindawi.com
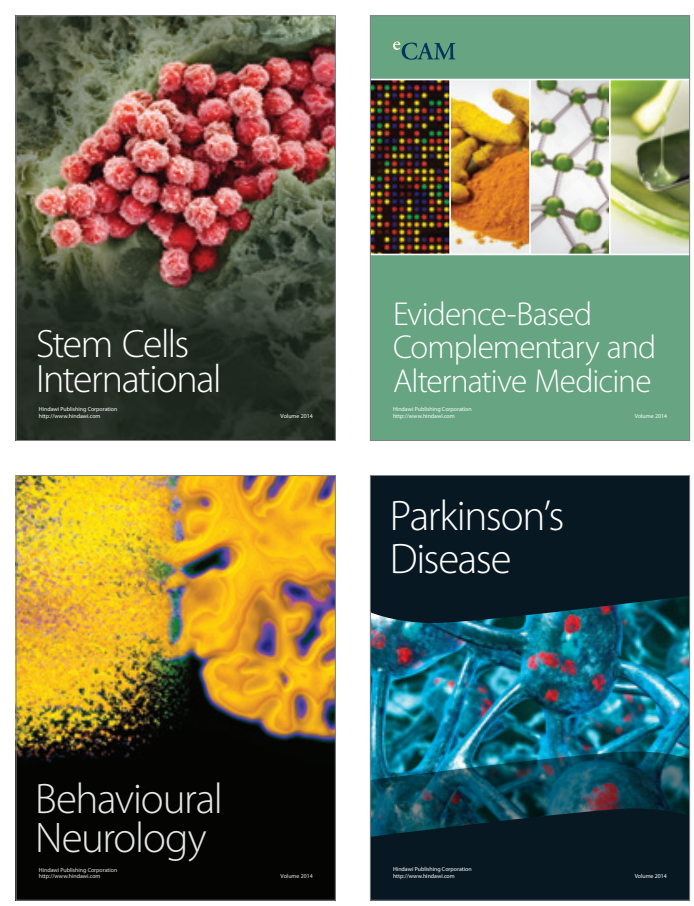

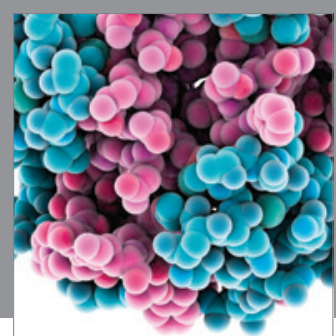

Journal of
Diabetes Research

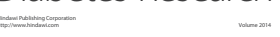

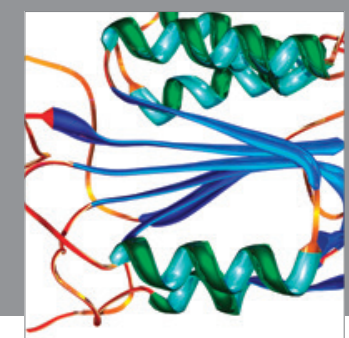

Disease Markers
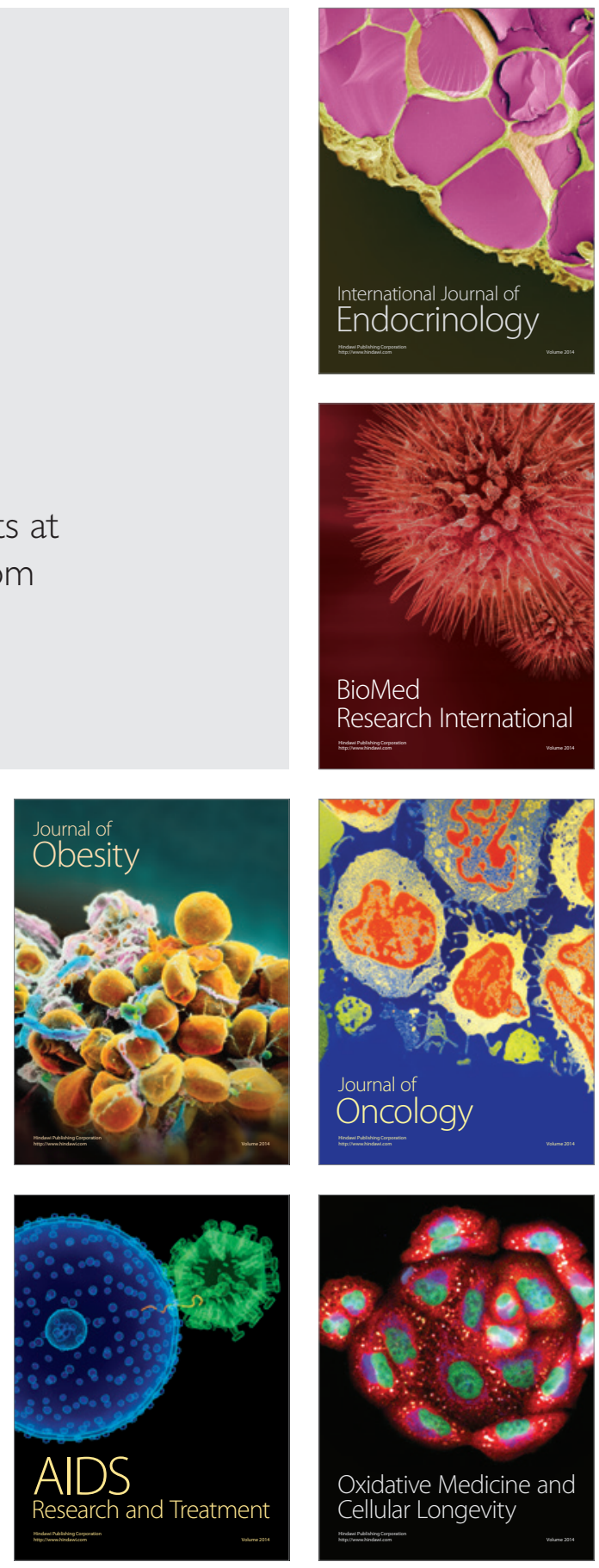